\title{
PENGUNGKAPAN FRAUDULENT FINANCIAL STATEMENT PADA BANK UMUM SYARIAH
}

\author{
Puspa Kartika Cahyani ${ }^{1}$, Arna Asna Annisa ${ }^{2}$ \\ Institut Agama Islam Negeri Salatiga ${ }^{1,2}$ \\ puspakartika2104@gmail.com ${ }^{1}$ arnaannisa@iainsalatiga.ac.id ${ }^{2}$
}

\begin{abstract}
This research purpose to examine the effect on fraud diamond toward the fraudulent financial statement. This research uses sampel in islamic comersial banks that listed in financial service authority from 2015-2019. The numbers of population in this research are 14 Islamic Commercial Banks with five years observation. Based on purpossive method, total of research samples are 55 financial statements. The hypothesis in this research is tested by multiplied regression analyze. The result of this research indicates that the financial stability and rationalization effect toward the fraudulent financial statement. However, financial target, external pressure, ineffective monitoring, and capability don't effect toward the fraudulent financial statement.
\end{abstract}

Keywords: Fraud Diamond, Financial Statement, Islamic Bank

\section{PENDAHULUAN}

Saat ini di Indonesia di kenal dua jenis bank yaitu bank yang melaksanakan kegiatan usahanya secara konvensional dan bank yang menjalankan usahanya berdasarkan prinsip syariah atau yang disebut bank syariah. Dengan berlandaskan hukum Islam (syariah) dan menggunakan sistem bagi hasil, bank syariah diharapkan mampu mencapai tujuan-tujuan yaitu demi kemaslahatan umat. Negara Indonesia memiliki jumlah umat muslim yang banyak, untuk memenuhi kebutuhan umat muslim dalam menerapkan prinsip Islam dibidang lembaga keuangan di Indonesia, menjadi salah satu alasan hadirnya lembaga keuangan syariah termasuk bank syariah. Perbankan syariah merupakan bagian dari entitas syariah yang berfungsi sebagai lembaga perantara keuangan, diharapkan mampu menampilkan dirinya secara baik dibandingkan dengan perbankan dengan sistem lain yaitu perbankan berbasis bunga (Suwiknyo, 2010).

Sebagai lembaga yang berpedoman pada hukum Islam, lembaga keuangan syariah dituntut untuk memiliki performa lebih baik dimata masyarakat sehingga masyarakat tertarik untuk menginvestasikan dananya pada bank syariah. Gambaran baik ataupun buruknya serta kinerja perbankan syariah dapat dilihat melalui laporan keuangan.Laporan keuangan disusun berdasarkan 
PSAK No. 101 tentang Penyajian Pelaporan Keuangan Syariah (Junita, 2016).Pentingnya infromasi yang disajikan oleh perusahaan dalam laporan keuangan dapat memotivasi manajemen perusahaan untuk terus meningkatkan kinerja, agar informasi yang ditampilkan dapat memuaskan para penggunan laporan keuangan.Namun pada kenyataannya laporan keuangan dapat menjadi celah bagi manajemen perusahaan untuk melakukan kecurangan karena tidak mampu mencapai tujuan yang ditargetkan (Putri, 2015).

Berdasarkan laporan Association of Certified Fraud Examiners (ACFE), pada tahun 2020 kerugian yang diakibatkan oleh kecurangan secara global menduduki peringkat tertinggi dari tiga kasus lainnya yaitu Asset Misappropriation, Corruption, dan Financial Statement Fraud. dalam grafik menunjukkan informasi sebagai berikut:

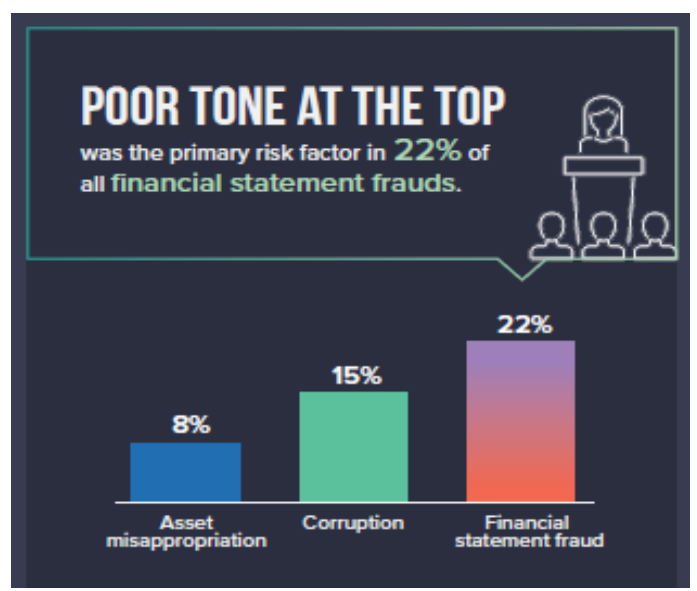

\section{Gambar 1. Jenis Tingkat Kasus Fraud Tahun 2020}

Sumber: (Report To The Nations, 2020 Global Study on Occupational Frand and Abuse, 2020)

Berdasakan gambar di atas diketahui kasus financial statement fraud berada pada prosentase teringgi. Dimana pada tahun 2020 ditemukan kecurangan yang terjadi pada Asset Misappropriation (8\%), kemudian Corruption (15\%), dan jumlah paling banyak adalah Financial Statement Fraud (22\%). Berdasarkan survei yang dilakukan secara global yang dilakukan oleh Association of Certified Fraud Examiner (ACFE) pada tahun 2020 menunjukkan fakta bahwa sektor keuangan dan perbankan justru merupakan sektor yang terbanyak mengalami kasus frand dibanding sektorsektor yang lain. Kasus-kasus dan survei ini kemudian menjadi salah satu alasan mengapa penelitian ini dilakukan.

Tindakan pemanipulasian dalam penyajian laporan keuangan termasuk dalam bentuk tindakan kecurangan atau fraud. Kecurangan yang diupayakan untuk mengelabui atau memperdaya pihak lain dengan tujuan untuk memperoleh manfaat pribadi. Kecurangan 
Cahyani \& Annisa. Pengungkapan Fraudulent Financial Statement Pada Bank Umum Syariah

pelaporan keuangan merupakan suatu usaha yang dilakukan dengan sengaja oleh perusahaan untuk menyesatkan para pengguna laporan keuangan, terutama investor dan kreditor, dengan menyajikan dan merekayasa nilai material dari laporan keuangan.Unsur syariah dalam perbankan syariah tidak menjamin suatu lembaga terbebas dari tindak kecurangan (fraud) (Junita, 2016). Adanya kasus di Bank BJB Syariah yang ditulis oleh Arief dalam web m.bisnis.com terdapat 4 internal fraud, kasus dugaan kredit fiktif yang merugikan perseroan senilai Rp 548 miliar. Berdasarkan laporan Good Corporate Governance (GCG) 2018 yang diterbitkan perseroan, tercatat ada 4 kasus penyimpangan (internal fraud) yang memengaruhi kegiatan operasional bank dan kondisi keuangan secara signifikan pada tahun lalu.Dampak penyimpangan atau kerugian yang ditimbulkan akibat internal fraud ini masing-masing senilai lebih dari Rp 100 juta.Hingga laporan itu dirilis, keempat kasus tersebut masih dalam internal BJB Syariah.Selain itu juga terdapat kasus dari salah satu bank syariah yang di lansir dari detiknews yaitu Bank Syariah Mandiri (BSM). BSM terkena kasus adanya penggelapan dana yang dilakukan oleh pegawai BSM pada tahun 2014. Modus yang digunakan adalah pihak bank bekerjasama dengan oknum luar untuk mencairkan dana SKBN (Surat Kredit Berdokumen Dalam Negeri) sehingga menyebabkan bank mengalami kerugian sebesar 75 Milyar. Dari kasus tersebut dapat menimbulkan kemungkinan bahwa adanya kemungkinan kecurangan-kecurangan yang terjadi pada perbankan syariah.

Penelitian mengenai faktor-faktor fraud diamond dalam mendeteksi kecurangan laporan keuangan sebelumnya telah dilakukan, dan saat ini semakin berkembang. Namun pada penelitian terdahulu terdapat perbedaan hasil penelitian sehingga menimbulkan adanya Research Gap.Salah satu penelitian yang dijadikan acuan penelitin ini adalah penelitian yang dilakukan oleh (Putri, 2015).Penelitian ini berfokus pada analisis Frand Diamond dalam mendeteksi kecurangan laporan keuangan yang diproksikan dengan manajemen laba.Penelitian ini dilakukan di perusahaan perbankan yang terdaftar di BEI. Hasilnya variabel personal financial need berpengaruh sedangkan yang lain tidak. Sedangkan dalam penelitian Saputra \& Kusumaningrum (2015) juga terdapat perbedaan penelitian dimana semua variabel berpengaruh sedangkan financial target dan ineffective monitoring tidak.

Perbedaan penelitian ini dengan penelitian terdahulu adalah penelitian ini menggunakan objek Bank Umum Syariah dengan periode pengamatan tahun 2015-2019.Sedangkan pada penelitian sebelumnya tahun penelitian yang digunakan merupakan tahun sebelum 2019.Selain objek dan tahun yang berbeda penelitian ini juga menggunakan variabel yang berbeda. 
Berdasarkan uraian di atas, maka penulis tertarik untuk melakukan penelitian dengan judul "Analisis Fraud Diamond Dalam Mendeteksi Fraudulent Financial Statement (Studi Pada Bank Umum Syariah Periode 2015-2019"

\section{STUDI LITERATUR}

Teori keagenan mendasarkan pada hubungan prinsipal yaitu para pemegang saham dengan agen yaitu manajemen atau perusahaan (Jensen \& H.Meckling, 1976).Teori keagenan beranggapan bahwa setiap individu berperilaku sesuai dengan kepentingannya masing-masing dan menimbulkan kepentingan yang bertentangan. Namun, hal ini menimbulkan permasalahan yaitu para agen memiliki kepentingan untuk mendapatkan kompensasi yang besar atas hasil kerjanya sedangkan para prinsipal atau pemegang saham menginginkan return yang tinggi atas investasinya (Hanifa \& Laksito, 2015). Perbedaaan tujuan inilah yang menimbulkan conflict of interest atau kepentingan konflik diantara pihak agen dan prinsipal.Hubungan diantara keduanya dapat mengarah pada suatu kondisi ketidakseimbangan infromasi antara prinsipal dan agent atau disebut sebagai asimetri infromasi (Amara, Amar, \& Jarboui, 2013).

Fraud diamond menurut Wolfe \& Hermanson (2004) adalah penyempurnaan dari frand yang dirangkum model triangle oleh (Cressey, 1953). Wolfe \& Hermanson (2004) menyatakan: "banyak penipuan tidak telah terjadi tanpa orang yang tepat dengan kemampuan detail penipuan". Unsur-unsur teori Fraud Diamond adalah tekanan, peluang, rasionalitas, dan kapabilitas. Menurut Wolfe \& Hermanson (2004) berpendapat bahwa kecurangan tidak akan terjadi tanpa adanya orang yang tepat dengan kemampuan yang tepat pula. Adanya elemen capability sebagai salah satu risiko terjadinya kecurangan dan menyimpulkan bahwa perubahan direksi dapat mengindikasikan terjadinya fraud.

Berdasarkan kepada landasan teori, beberapa penelitian terdahulu yang telah dilakukan oleh beberapa peneliti, dan rumusan masalah diatas maka hipotesis yang diajukan sebagai berikut :

Kenaikan financial target pada perusahaan perbankan merupakan suatu tekanan bagi perusahaan.Dengan kondisi demikian, manajemen terdorong untuk melakukan manipulasi agar mencapai target laba yang sudah ditetapkan, sehingga adanya indikasi kecurangan dalam penyusunan laporan keuangan. Hal ini sejalan dengan penelitian Septriani \& Handayani (2018) dan Junita (2016) yang menyatakan bahwa financial target berpengaruh positif terhadap kemungkinan terjadinya fraud.

$\mathrm{H}_{1}$ :Financial target berpengaruh terhadap fraudulent financial statement

Manajemen sering kali mendapat tekanan untuk mengelola perusahaan agar perusahaan tetap stabil.Salah satu keadaan yang memaksa sebuah perusahaan untuk menampilkan keuangan 
Cahyani \& Annisa. Pengungkapan Fraudulent Financial Statement Pada Bank Umum Syariah

yang stabil yaitu dengan pertumbuhan aset perusahaan yang stabil, sehingga dapat memicu daya tarik bagi investor, kreditor maupun pengambil keputusan lainnya. Hal inilah yang memicu manajemen untuk melakukan kecurangan guna menutupi kondisi stabilitas yang buruk (Nugraheni \& Triatmoko, 2017). Hal tersebut sejalan dengan penelitian Sari (2016), Yulia \& Basuki (2016), dan Indriani (2017) bahwa financial stability berpengaruh terhadap fraudulent financial statement.

$\mathrm{H}_{2}$ :Financial Stability berpengaruh terhadap fraudulent financial statement

Tekanan eksternal dapat terjadi ketika perusahaan menghadapi kesulitan besar dalam memenuhi pinjaman kredit yang memiliki rasio tinggi.Risiko kredit yang tinggi, maka terdapat kekhawatiran bahwa pada nantinya perusahaan tidak mampu untuk membalikkan pinjaman modal yang diberikan. Oleh karena itu, perusahaan rentan melakukan kecurangan pada laporan keuangan dengan cara menyelamatkan diri dari kondisi yang demikian agar tetap dianggap mampu untuk mengembalikan pinjaman. Hal itu didukung dengan penelitian Sihombing \& Rahardjo (2014), Saputra \& Kusumaningrum (2015) dan Junita (2016) bahwa external pressure berpengaruh terhadap kemungkinan terjadinya fraudulent financial statement.

\section{$\mathrm{H}_{3}$ : External Pressure berpengaruh terhadap fraudulent financial statement}

Hasil penelitian terdahulu oleh Putri (2015), Beasley menyimpulkan bahwa masuknya dewan komisaris yang berasal dari luar perusahaan meningkatkan efektivitas dewan tersebut dalam mengawasi manajemen untuk mencegah kecurangan laporan keuangan. Hasil ini diperkuat oleh Skousen et al. (2009) yang membuktikan bahwa kecurangan lebih sering terjadi pada perusahaan yang lebih sedikit memiliki anggota dewan komisaris eksternal. Hal tersebut di dukung dengan penelitian yang di lakukan oleh Indriani (2017) dan Septriani \& Handayani (2018) bahwa ineffective monitoring berpengaruh terhadap fraudulent financial statement.

$\mathrm{H}_{4}$ :Ineffective monitoring berpengaruh terhadap fraudulent financial statement

Rasionalisasi (rationalization) merupakan pembenaran terhadap tindakan kecurangan yang dilakukan oleh pelaku. Menurut Sihombing \& Rahardjo (2014) menyatakan bahwa total akrual merupakan cerminan dari aktivitas perusahaan keseluruhan. Tingkat akrual perusahaan akan beragam tergantung dari keputusan manajemen terkait kebijakan tertentu. Hasil penelitian Sihombing \& Rahardjo, (2014) membuktikan bahwa rasionalisasi berpengaruh terhadap kecurangan laporan keuangan. Hal tersebut juga didukung dengan penelitian Sari (2016) dan Septriani \& Handayani (2018) yang membuktikan bahwa rasionalisasi berpengaruh terhadap kecurangan laporan keuangan.

$\mathrm{H}_{5}$ :Rationalization berpengaruh terhadap fraudulent financial statement 
Perubahan direksi tidak selamanya berdampak baik bagi perusahaan.Perubahan direksi bisa menjadi suatu upaya perusahaan untuk memperbaiki kinerja direksi sebelumnya dengan melakukan perubahan susunan direksi ataupun perekrutan direksi yang baru yang dianggap lebih berkompeten dari direksi sebelumnya. Sementara disisi lain, pergantian direksi bisa jadi merupakan upaya perushaan untuk menyingkirkan direksi yang dianggap mengetahui kecurangan yang di lakukan perusahaan serta perubahan direksi dianggap akan membutuhkan waktu adaptasi sehingga kinerja awal tidak maksimal. Hal tersebut sejalan dengan penelitian Saputra \& Kusumaningrum (2015), Putri (2015), dan Septriani \& Handayani (2018) yang menyatakan bahwa capability berpengaruh terhadap fraud.

$\mathrm{H}_{6}$ :Capability berpengaruh terhadap fraudulent financial statemen

\section{METODOLOGI}

Jenis penelitian yang akan digunakan untuk penelitian adalah dengan pendekatan kuantitatif untuk menganalisis fraud diamond dalam mendeteksi fraudulent financial statement di Bank Umum Syariah periode 2015-2019. Menurut Sugiyono (2012) pendekatan kuantitatif adalah metode penelitian yang berlandaskan pada filsafat positivisme, digunakan untuk meneliti pada populasi atau sempel tertentu, pengumpulan data menggunakan instrumen penelitian, analisis data bersifat kuantitatif/statistik, dengan tujuan untuk menguji hipotesis yang telah ditetapkan. Menurut Sugiyono (2012) penelitian deskriptif yaitu, penelitian yang dilakukan untuk mengetahui nilai variabel mandiri, baik satu variabel atau lebih (independen) tanpa membuat perbandingan, atau menghubungkan dengan variabel yang lain. Metode pengumpulan data yang digunakan adalah metode kepustakaan dengan menggunakan data yang berasal dari jurnal penelitian, buku literature, laporan keuangan dan penelitian terdahulu.

Populasi dalam penelitian ini adalah 14 Bank Umum Syariah yang terdaftar di Otoritas Jasa Keuangan (OJK). Data didapat dari website resmi Otoritas Jasa Keuangan (OJK) www.ojk.go.id yaitu sebagai berikut:

Tabel 1. Bank Umum Syariah

\begin{tabular}{cl}
\hline No & Bank Umum Syariah \\
\hline $\mathbf{1 .}$ & PT. Bank Aceh Syariah \\
$\mathbf{2 .}$ & PT BPD Nusa Tenggara Barat Syariah \\
$\mathbf{3 .}$ & PT. Bank Muamalat Indonesia \\
$\mathbf{4 .}$ & PT. Bank Victoria Syariah \\
$\mathbf{5 .}$ & PT. Bank BRISyariah \\
$\mathbf{6 .}$ & PT. Bank Jabar Banten Syariah \\
$\mathbf{7 .}$ & PT. Bank BNI Syariah \\
\hline
\end{tabular}




\begin{tabular}{cl}
\hline 8. & PT. Bank Syariah Mandiri \\
9. & PT. Bank Mega Syariah \\
10. & PT. Bank Panin Dubai Syariah \\
11. & PT. Bank Syariah Bukopin \\
12. & PT. BCA Syariah \\
13. & PT. Bank Tabungan Pensiunan Nasional Syariah \\
14. & PT. Maybank Syariah Indonesia \\
\hline
\end{tabular}

Menurut Sugiyono, (2012) sampel adalah sebagian dari jumlah dan karakteristik yang dimiliki oleh populasi tersebut. Untuk menentukan jumlah sampel dilakukan sebuah sampling.

Tabel 2. Sampel Bank Umum Syariah

\begin{tabular}{clcc}
\hline No & \multicolumn{1}{c}{ Kriteria Sampel } & $\begin{array}{c}\text { Tidak Masuk } \\
\text { Kriteria }\end{array}$ & $\sum$ \\
\hline 1. & $\begin{array}{l}\text { Bank Umum Syariah selama periode 2015-2019 secara } \\
\text { berturut-turut dan sudah terdaftar dari sebelum 2014 }\end{array}$ & - & 14 \\
2. $\quad \begin{array}{l}\text { Bank Umum Syariah yang mempublikasikan laporan } \\
\text { keuangan tahunan selama periode 2015-2019 }\end{array}$ & 2 & 12 \\
3. $\quad \begin{array}{l}\text { Data yang berkaitan dengan variabel penelitian tersedia } \\
\text { dengan lengkap } \\
\text { Jumlah sampel penelitian (x 5 tahun) }\end{array}$ & 35 \\
\hline
\end{tabular}

Variabel yang digunakan dalam penelitian ini adalah financial statement frand yang diproksikan dengan earning manajement. Manajemen laba dapat diukur melalui discretionary accrual yang dihitung dengan cara menyelisihkan total accruals (TA) dan nondiscretionary accruals (NDA). Discretionary accruals (DA) merupakan tingkat akrual yang tidak normal yang berasal dari kebijakan manajemen untuk melakukan rekayasa terhadap laba sesuai dengan yang mereka inginkan.Dalam menghitung DA, digunakan Modified Jones Model.Alasan penggunaan model ini karena Modified Jones Model dapat mendeteksi manajemen laba (Sari, 2016). Perhitungan modified jones model dilakukan dengan cara berikut ini:

1) Mentabulasikan data-data yang dibutuhkan dan menghitung Total Accrual.

$$
T A_{i t}=N i_{i t}-C F O_{i t}
$$

2) Mempersiapkan data untuk mendapatkan $\beta_{1}, \beta_{2}, \beta_{3}$ dengan melakukan regresi OLS pada persamaan berikut ini.

$$
\frac{T A_{i t}}{A_{i t-1}}=\beta_{1} \frac{1}{A_{i t-1}}+\beta_{2} \frac{\Delta R E V_{i t}}{A_{i t-1}}+\beta_{3} \frac{P P E_{i t}}{A_{i t-1}}+e
$$

3) Setelah mendapatkan nilai $\beta_{1}, \beta_{2}, \beta_{3}$ dari regresi OLS lalu memasukkan nilai-nilai tersebut pada persamaan berikut ini. 


$$
N D A_{i t}=\beta_{1}\left(\frac{1}{A_{i t-1}}\right)+\beta_{2}\left(\frac{\Delta R E V_{i t}}{A_{i t-1}}-\frac{\Delta R E C_{i t}}{A_{i t-1}}\right)+\beta_{3}\left(\frac{P P E_{i t}}{A_{i t-1}}\right)
$$

4) Selanjutnya menghitung discretionary accruals dengan cara sebagai berikut.

$$
D A C_{i t}=\frac{T A_{i t}}{A_{i t}}-N D A_{i t}
$$

Keterangan :

$\mathrm{DAC}_{\mathrm{it}}$ : Directionary Accrual perusahaan i pada periode $\mathrm{t}$

$\mathrm{TA}_{\text {it }} \quad$ : Total Accrual perusahaan i pada periode $\mathrm{t}$

$\mathrm{NDA}_{\mathrm{it}}$ : Non Directionary Accrual perusahaan i pada periode $\mathrm{t}$

$\mathrm{Ni}_{\mathrm{it}} \quad$ : Laba bersih perusahaan i pada periode $\mathrm{t}$

$\mathrm{CFO}_{\text {it }}$ : Arus kas Operasi perusahaan i pada periode $\mathrm{t}$

$\mathrm{A}_{\text {it }} \quad$ : Total aktiva perusahaan i pada periode $\mathrm{t}$

$\triangle \mathrm{REV}_{\mathrm{it}}$ : Selisih pendapatan pada periode $\mathrm{t}$ dengan periode $\mathrm{t}-1$

$\Delta \mathrm{REC}_{\mathrm{it}}$ : Selisih piutang pada periode t dengan periode $\mathrm{t}-1$

$\mathrm{PPE}_{\text {it }} \quad$ : Nilai Aktiva tetap (gross) perusahaan i pada periode $\mathrm{t}$

e : error

Variabel independen yang digunakan dalam penelitian ini merupakan variabel yang dikembangkan dari komponen fraud diamond yaitu pressure, opportunity, rationalization dan capability. Berikut penjelasan variabel independen yang digunakan dalam penelitian ini:

Tabel 3. Variabel Independen

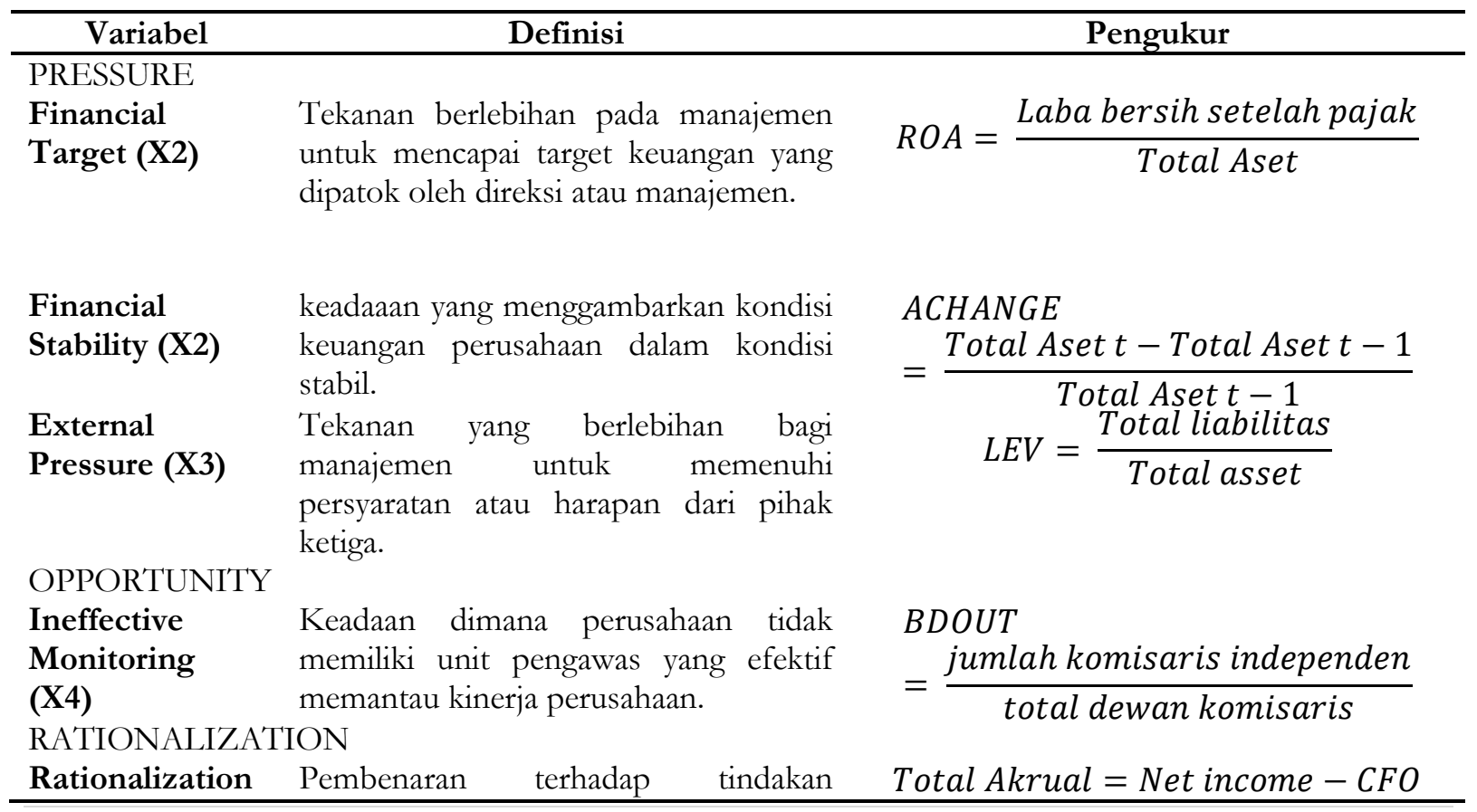




\begin{tabular}{lll}
\hline X5) & kecurangan yang dilakukan oleh pelaku. & \\
CAPABILITY & & \\
Capability (X6) & $\begin{array}{l}\text { Kemampuan dalam memanfaatkan } \\
\text { keadaan yang dapat mendoron tindakan } \\
\text { kecurangan. }\end{array}$ & $\begin{array}{l}\text { Variabel dummy, kode 1 jika terdapat } \\
\text { 0 jika tidak terdapat pergantian direksi. }\end{array}$ \\
\hline
\end{tabular}

Metode analisis ini digunakan untuk mendapatkan hasil yang pasti dalam mengolah data sehingga dapat dipertangungjawabkan.Adapun, metode analisis data yang digunakan adalah metode regresi linier berganda.Pengujian regresi linier berganda dapat dilakukan setelah model pada penelitian ini memenuhi syarat-syarat yaitu lolos dari uji asumsi klasik.Menurut Ghozali (2011) menyatakan bahwa uji asumsi klasik digunakan untuk mendapatkan model regresi yang baik, terbebas dari penyimpangan data yang terdiri dari uji normalitas, multikolonieritas, autokorelasi, dan heteroskedastisitas. Adapun model regresi berganda digambarkan dalam bentuk sebagai berikut:

$Y=\alpha+\beta_{1} X_{1}+\beta_{2} X_{2}+\beta_{3} X_{3}+\beta_{4} X_{4}+\beta_{5} X_{5}+\beta_{6} X_{6}+e$

Keterangan :

$\mathrm{Y} \quad$ : financial statement fraud

$\alpha \quad$ : Koefisien regresi konstanta

$\beta_{1,2,3,4,5,6}$ : Koefisien regresi masing-masing proksi

$\mathrm{X}_{1} \quad$ : financial target

$\mathrm{X}_{2} \quad$ : financial stability

$\mathrm{X}_{3} \quad$ : external pressure

$\mathrm{X}_{4} \quad$ : ineffective monitoring

$\mathrm{X}_{5} \quad$ : rationalization

$\mathrm{X}_{6} \quad$ : capability

e : error

\section{HASIL DAN PEMBAHASAN}

Berdasarkan hasil analisis data diatas, mengenai pengaruh enam variabel independen yakni financial target, financial stability, external pressure, ineffective monitoring, rationalization, dan capability terhadap fraudulent financial statement, maka dapat disimpulkan hasil pengujian signifikasi variabel independen secara parsial sebagaimana pada pembahasan berikut:

\section{Pengaruh financial target terhadap fraudulent financial statement}

Hasil penghitungan statistik menunjukkan hasil sebesar 0,723 yang berarti lebih besar dari $\alpha(0,05)$ nilai koefisien beta sebesar $-0,475$ yang menandakan bahwa hipotesis pertama yaitu financial terget (ROA) berpengaruh terhadap fraudulent financial statement ditolak. Maka dapat disimpulkan bahwa financial target yang diproksikan dengan ROA tidak berpengaruh negatif 
terhadap fraudulent financial statement.Hal ini berarti, ketika kondisi ROA bank syariah naik maka hal ini berarti bank syariah mampu untuk menghasilkan laba dari aset perusahaan.

Penelitian ini tidak sejalan dengan penelitian (Junita, 2016). Namun penelitian ini sejalan dengan penelitian yang di lakukan oleh Sririzky (2017) yang menyatakan bahwa tidak berpengaruhnya ROA terhadap fraudulentfinancial statement bisa disebabkan karena manajer menganggap besar atau kecilnya ROA masih dinilai wajar dan masih bisa untuk dicapai. Sehingga pada bank syariah ROA tidak dapat mendukung untuk digunakan auditor sebagai alat deteksi fraudulent financial statement.

Hasil penelitian ini sejalan dengan teori agensi, target keuangan memiliki hubungan dengan agen dan prinsipal. Dimana agen melaksankan kewajiban dan menampilkan performa perusahaan sebaik mungkin sehingga dapat tercapainya target keuangan yang telah direncanakan. Sedangkan prinsipal memberikan bonus kepada agen atas hasil kerja kerasnya.Kondisi ini menimbulkan dampak risiko fraud rendah. Dalam tahun penelitian yang digunakan dalam penelitian ini financial target tidak memiliki pengaruh terhadap fraudulent financial statement karena menajemen perusahaan melakukan kinerja keuangan secara hati-hati dan kemungkinan terjadinya fraudulent financial statement sangat kecil.

\section{Pengaruh financial stability terhadap fraudulent financial statement}

Hasil penghitungan statistik menunjukkan hasil sebesar 0,000 yang berarti lebih kecil dari $\alpha(0,05)$ nilai koefisien beta sebesar 0,254 yang menandakan bahawa hipotesis kedua yaitu financial stability (ACHANGE) berpengaruh terhadap fraudulent financial statement diterima. Maka dapat disimpulkan bahwa financial stability yang diproksikan dengan ACHANGE berpengaruh positif terhadap fraudulent financial statement.

Hasil penelitian ini sejalan dengan penelitian yang dilakukan oleh Sari (2016), Septriani \& Handayani (2018), dan Saputra \& Kusumaningrum (2015) dimana financial stability memiliki pengaruh terhadap fraudulent financial statement. Namun berbeda dengan penelitian yang dilakukan oleh Nugraheni \& Triatmoko (2017) yang dalam penelitiannya menyimpulkan bahwa financial stability tidak berpengaruh terhadap fraudulent financial statement.

Hasil penelitian ini menunjukkan bahwa perubahan total aset dalam perusahaan menyebabkan perusahaan melakukan kecurangan. Manajemen sering sekali mendapatkan tekanan untuk menunjukkan bahawa perusahaan telah mampu mengelola aset dengan baik, sehingga laba yang dihasilkan tercapai dan menghasilkan return yang tinggi untuk investor, karena besarnya total aset mempengaruhi daya tarik tersendiri bagi para investor, kreditor, dan pemilik perusahaan. Namun, ketika total aset mengalami penurunan hal itu akan membuat daya tarik menurun karena 
Cahyani \& Annisa. Pengungkapan Fraudulent Financial Statement Pada Bank Umum Syariah

dianggap bahwa kondisi keuangan perusahaan tidak stabil. Oleh sebab itu, manajemen menggunakan laporan keuangan sebagai alat untuk menutupi kondisi keuangan yang tidak stabil dengan melakukan fraud.Berdasarkan penjelasan tersebut, maka dalam tahun 2015-2019 manajamen melakukan tindakan pemanipulasian laporan keuangan supaya perusahaan dianggap stabil guna menaikkan daya tarik terhadap investor, kreditor, dan pemilik perusahaan.Sehingga financial stability berpengaruh terhadap fraudulent financial statement.

\section{Pengaruh external pressure terhadap fraudulent financial statement}

Hasil penghitungan statistik menunjukkan sebesar 0,847 yang berarti lebih besar dari $\alpha$ $(0,05)$ nilai koefisien beta sebesar -0,24 yang menandakan bahwa hipotesis ketiga yaitu external pressure (LEV) berpengaruh terhadap fraudulent financial statement ditolak. Artinya bahwa external pressure tidak berpengaruh terhadap fraudulent financial statement.

Hasil penelitian ini tidak sejalan dengan penelitian Saputra \& Kusumaningrum (2015) dan Junita (2016) yang menyatakan bahwa external pressure berpengaruh terhadap fraudulent financial statement. Namun penelitian ini sejalan dengan penelitian Septriani \& Handayani (2018), Sririzky (2017), dan Yulia \& Basuki (2016) dimana external pressure tidak berpengaruh terhadap fraudulent financial statement.

Hasil penelitian ini yang menyatakan bahwa external pressure tidak berpengaruh terhadap fraudulent financial statement.External pressure yang berupa risiko kredit yang tinggi akibat besarnya jumlah pinjaman yang mendorong manajemen untuk melakukan manipulasi terhadap laporan keuangan yang bertujuan untuk meyakinkan kreditur bahwa perusahaan mampu melunasi pinjamannya. Semakin tinggi rasio leverage maka lebih besar kemungkinan terjadinya tindakan kecurangan. Berdasarkan hasil uji yang telah dilakukan dalam perusahaan perbankan syariah tidak menjadi tekanan bagi manajemen untuk melakukan kecurangan dalam menyusun laporan keuangan.Hal itu karena perusahaan mampu membayar utangnya dan lebih memilih menerbitkan saham kembali untuk memperoleh modal usaha.Dalam periode penelitian tahun 2015-2019 terbukti bahwa perusahan perbankan mampu melunasi pinjamannya, sehingga tidak melakukan tindakan kecurangan dalam penyusunan laporan keuangan.

\section{Pengaruh ineffective monitoring terhadap fraudulent financial statement}

Hasil penghitungan statistik menunjukkan hasil sebesar 0,543 yang berarti lebih besar dari $\alpha(0,05)$ nilai koefisien beta sebesar 0,018 yang menandakan bahwa hipotesis keempat yaitu ineffective monitoring (BDOUT) berpengaruh terhadap fraudulent financial statement ditolak. Artinya bahwa ineffective monitoring tidak berpengaruh terhadap fraudulent financial statement. 
Hasil penelitian ini tidak sejalan dengan penelitian Septriani \& Handayani (2018) dan Sririzky (2017) yang menyatakan bahwa ineffective monitoring berpengaruh terhadap fraudulent financial statement. Namun, penelitian ini sejalan dengan penelitian Saputra \& Kusumaningrum (2015), Putri (2015), Indriani (2017), dan Yulia \& Basuki (2016) dimana ineffective monitoring tidak berpengaruh terhadap fraudulent financial statement.

Hasil penelitian yang tidak signifikan ini menunjukkan ketidakefektifan fungsi kontrol anggota komisaris independen terhadap laporan keuangan.Keberadaan anggota komisaris independen dalam perusahaan tidak dapat menjalankan tugasnya dalam memonitor pelaporan keuangan sehingga keberadaan anggota komisaris independen gagal dalam mendeteksi fraudulent financial statement.Karena fungsi dari komisaris independen yaitu menilai kinerja dari perusahaan dan memonitoring kinerja dari manajemen agar tercipta perusahaan yang good corporate govermance serta tercipta iklim yang lebih objektif dan independen.Berdasarkan penjelasan tersebut maka pada tahun yang digunakan dalam penelitian ini jumlah komisaris independen dalam perusahaan perbankan tidak memiliki pengaruh terhadap fraudulent financial statement.

\section{Pengaruh rationalization terhadap fraudulent financial statement}

Hasil pengamatan statistik menunjukkan hasil sebesar 0,000 yang berarti lebih kecil dari $\alpha$ $(0,05)$ dan nilai koefisien beta sebesar 0.908 yang menandakan bahwa hipotesis kelima yaitu rationalization (TATA) berpengaruh terhadap fraudulent financial statement. Maka dapat disimpulkan bahwa rationalization berpengaruh positif terhadap fraudulent financial statement. Hal ini berarti bahwa semakin tinggi nilai total akrual diprediksi akan meningkatkan fraudulent financial statement.

Hasil penelitian ini tidak sejalan dengan penelitian Putri (2015) yang menyatakan bahwa rationalization tidak berpengaruh terhadap fraudulent financial statement. Namun sejalan sengan penelitian Febrianto et al. (2014), Saputra \& Kusumaningrum (2015), Septriani \& Handayani (2018), dan Sririzky (2017) yang menyatakan bahwa rationalization berpangaruh terhadap fraudulent financial statement.

Hasil penelitian yang positif memberikan bukti bahwa perusahaan perbankan selama tahun pengamatan yaitu pada tahun 2015-2019 melakukan upaya untuk menaikkan laba perusahaan.Earnings management yang dilakukan dengan cara menaikkan laba terjadi karena kemungkinan manajemen bersikap optimis dalam melaporkan kinerjanya, yaitu dengan mengakui pendapatan yang akan datang menjadi pendapatan sekarang (Septriani \& Handayani, 2018).

\section{Pengaruh capability terhadap fraudulent financial statement}

Hasil penghitungan statistik menunjukkan hasil sebesar 0,351 yang berarti lebih besar dari $\alpha(0,05)$ dan nilai koefisien beta sebesar $-0,017$ yang menandakan bahwa hipotesis keenam yaitu 
capability (DCHANGE) berpengaruh terhadap fraudulent financial statement ditolak. Artinya capability tidak memiliki pengaruh terhadap fraudulent financial statement.

Hasil penelitian ini tidak sejalan dengan penelitian Saputra \& Kusumaningrum (2015), Septriani \& Handayani (2018), dan Putri (2015) yang menyatakan bahwa direktur memiliki kemampuan dalam melakukan tindak kecurangan, karena mereka dianggap mengetahui celahcelah dan pandai melihat peluang dalam fungsi tertentu yang berpotensi untuk dilakukannya kecurangan. Kecurangan yang sering dilakukan direksi adalah manajemen laba. Direksi memiliki kemampuan khusus dalam melakukan kecurangan seperti manajemen laba dan penerapan kebijakan akuntansi tertentu sesuai dengan tujuannya, dengan cara mempengaruhi manajer beserta bawahannya yang lain untuk dapat mengikuti maksud dan tujuannya. Namun sejalan dengan penelitian (Febrianto et al., 2014).

Hasil penelitian ini mengemukakan bahwa besar kecilnya tingkat pergantian direksi tidak mempengaruhi untuk melakukan kecurangan dalam laporan keuangan.Ditolaknya hipotesis dikarenakan adanya pengawasan yang efektif dari dewan komisaris terhadap setiap kinerja manajemen, sehingga dalam tahun penelitian ini perubahan direksi yang dilakukan oleh perusahaan perbankan tidak memiliki pengaruh terhadap fraudulent financial statement.Selain itu perubahan direksi bisa terjadi karena ada pengunduran diri atau karena direksi sebelumnya telah meninggal dunia sehingga untuk mengisi kekosongan posisi tersebut perusahan melakukan perubahan penyusunan direksi.Pergantian direksi juga dilakukan karena perusahaan menginginkan direksi yang lebih kompeten dari sebelumnya, karena direksi yang lebih kompeten dari sebelumnya dianggap efektif untuk memungkinkan terjadinya peningkatan kinerja perusahaan yang lebih baik dari sebelumnya.Struktur anggota yang terjadi pada dewan direksi tidak terlalu berpengaruh dalam praktik manajemen laba.

\section{SIMPULAN}

Berdasarkan data yang dikumpulkan dari hasil pengujian yang telah dilakukan dengan menggunakan uji regresi berganda, maka dari 6 hipotesis yang diajukan dapat diambil kesimpulan, yaitu: (a) Variabel financial target tidak memiliki pengaruh terhadap fraudulent financial statement pada Bank Umum Syariah yang terdaftar di Otoritas Jasa Keuangan. (b) Variabel financial stability memiliki pengaruh terhadap fraudulent financial statement pada Bank Umum Syariah yang terdaftar di Otoritas Jasa Keuangan. (c) Variabel external pressure tidak memiliki pengaruh terhadap fraudulent financial statement pada Bank Umum Syariah yang terdaftar di Otoritas Jasa Keuangan. (d) Variabel ineffective monitoring tidak memiliki pengaruh terhadap fraudulent financial statement pada Bank Umum Syariah yang terdaftar di Otoritas Jasa Kuangan. (e) Variabel 
rationalization memiliki pengaruh terhadap fraudulent financial statement pada Bank Umum Syariah yang terdaftar di Otoritas Jasa Keuangan. (f) Variabel capability tidak memiliki pengaruh terhadap fraudulent financial statement pada Bank Umum Syariah yang terdaftar di Otoritas Jasa Keuangan.

\section{REFERENSI}

Association of Certified Fraud Examining. (2016). Report to the nation on occupational frand and abuse. 2014 Global Fraud Study.

Amara, I., Amar, A. B., \& Jarboui, A. (2013). Detecting of Fraud in Financial Statement: French Companies as a Case Study. International Journal of Academic Research in Accounting.

Arief, T. (2019). Terjadi 4 Internal Frand di BJB Syariah Selama 2018. diakses 7 November 2019, pukul 10.44: m.bisnis.com.

Aulia, T. Z. (2018). Determinan Kecurangan Laporan Keuangan: Pengujian Teori Fraud Diamond. Prosiding Konferensi Nasional Ke-7 Asosiasi Program Pascasarjana Perguruan Tinggi Mubammadiyah, Aisyiyah (APPPTMA).

Cressey, D. (1953). The Internal Auditor as Fraud Buster. Managerial Auditing Journal.

Febrianto, H. G., \& Fitriana, A. I. (2018). Analisis Fraud Diamond Dalam Mendeteksi Fraudulent Financial Statement Pada Bank Perkreditan Rakyat Syariah (BPRS) di Banten dan Jawa Barat. Seminar Nasional Multidisiplin (Senamu), 36-41.

Ghazali, I. (2013). SPSS 21 Aplikasi Multivarian dengan Program SPSS edisi 7. Semarang: Badan Penerbit Universitas Diponegoro.

Hanifa, S. I., \& Laksito, H. (2015). Pengaruh Fraud Indicators Terhadap Fraudulent Financial Statement (Studi Empiris pada Perusahaan yang Listed di BEI Tahun 2008-2013). Diponegoro Journal of Accounting, 1-15.

Ikatan Akuntansi Indonesia. (2015). Pernyataan Standar Akuntansi.

Indriani, P. (2017). Fraud Diamond dalam Mendeteksi Kecurangan Laporan Keuangan. I-Finance, 164-168.

Jensen, M. C., \& H.Meckling, W. (1976). Theory of the Firm: Managerial Behavior, Agency Costs and Ownership Structure. Journal Of Financial Economics, 82-136.

Junita, N. (2016). Deteksu Kecurangan Laporan Keuangan Pebankan Syariah dalam Perspektif Fraud Triangle Theory (Studi empiris pada BUS tahun 2010-2014).

Kennedy, Samuel, \& Rahardjo. (2014). Analisis Fraud Diamond dalam Mendeteksi Fianancial Statement fraud ; Studi Empiris pada Perusahaan Manufaktur yang Terdaftar di Bursa efek Indonesia (BEI) Tahun 2010-2012. Jurnal EKonomi dan Bisnis. 
Cahyani \& Annisa. Pengungkapan Fraudulent Financial Statement Pada Bank Umum Syariah

Kusumawardhani, P. (2013). Deteksi Financial Statement Fraud dengan Analisis Fraud Triangle pada Perusahaan yang Terdaftar DI BEI. Jumal Universitas Negeri Surabaya.

Listyaningrum, D., Paramita, P. D., \& Oemar, A. (2017). Pengaruh Financial Stability, External Pressure, Financial Target, Ineffective Monitoring dan Rasionalisasi terhadap Kecurangan Pelaporan Keuangan (Fraud) pada Perusahaan Manufaktur di BEI Tahun 2012-2015. Ekonomi-Akuntansi, 1-14.

Martono, N. (2017). Metode Penelitian Kuantitatif: Analisis Isi dan Analisis Data Sekunder. Jakarta: RajaGrafindo Persada.

Mujib, A. (2017). Syari'ah Fraud Model : Sebuah Konsep Dasar. Jurnal Ekonomi dan Bisnis, 112127.

Najib, H., \& Rini. (2016). Analisis Faktor yang Mempengaruhi Fraud di Bank Syariah. Simposium Nasional Akuntansi XIX, 2-5.

Nugraheni, N. K., \& Triatmoko, H. (2017). Analisis Faktor-Faktor Yang Mempengaruhi Terjadinya Financial Statement Fraud: Perspektif Diamond Fraud Theory (Studi pada Perusahaan yang Terdaftar di BEI Periode 2014-2016). Jurnal Akuntansi dan Auditing.

Putri, R. A. (2015). Analisis Fraud Diamond dalam Mendeteksi Fraudulent Financial Statement (Studi Empiris pada Perusahaan yang Terdaftar di BEI Tahun 2011-2014).

Rahmayuni, S. (2017). Analisis Pengaruh Fraud Diamond terhadap Kecurangan Laporan Keuangan (Studi Empiris pada Perusahaan Manufaktur yang terdaftar di BEI tahun 2013-2016). Jurnal Akuntansi Fakultas Ekonomi, 13-15.

Rozmita. (2017). Fraud Penyebab dan Pencegahannya. Bandung: Alfabeta.

Salni, \& Baridwan. (2000). Teori Earning Management: Definisi, Pola dan Faktor yang Mendorong Manajemen Melakukan Earning Management. Jurnal Riset Akuntansi Indonesia, 19.

Saputra, M. A., \& Kusumaningrum, N. D. (2017). Analisis Faktor-Faktor yang Mempengaruhi Fraudulent Financial Reporting dengan Persepektif Fraud Pentagon pada Perusahaan Perbankan yang Terdaftar di BEI tahun 2011-2015. Jurnal Ekonomi dan Bisnis.

Sari, S. T. (2016). Pengaruh Financial Stability, External Pressure, Financial Targets, Ineffective Monitoring, Rationalization pada Financial Statement Fraud dengan Perspektif Fraud Triangle (Studi Empiris pada Perusahaan Perbankan Periode 2012-2014 yang Terdaftar Di BEI). JOM Fekon.

Septriani, Y., \& Handayani, D. (2018). Mendeteksi Kecurangan Laporan Keuangan dengan Analisis Fraud Pentagon . Jurnal Akuntansi, Kenangan dan Bisnis, 11-23. 
Sihombing, K. S., \& Rahardjo, S. N. (2014). Analisis Fraud Diamond dalam mendeteksi Financial Statement Fraud: Studi Empiris pada Perusahaan Manufaktur yang Terdaftar di Bursa Efek Indonesia (BEI) tahun 2010-2012. Diponegoro Journal of Accounting, 1-12.

Skousen, C., Smith, K., \& Wright, C. (2009). Detecting and Predicting Financial Satatement Fraud: The effectiveness of The Fraud Triangle and SAS No. 99. Corporate Governance and Firm Performance Advances in Financial Economics, 53-81.

Sririzky, S. H. (2017). Pengaru Fraud Triangle terhadap Deteksi Kecurangan Laporan Keuangan Perbankan Syariah Periode 2011-2016.

Sugiyono. (2012). Metode Penelitian Kuantitatif, Kualitatif, dan R\&D. Bandung: Alfabeta.

Summers, S. L., \& Sweeney, J. T. (1998). Fraudulently Misstated Financial Statements and Insider Tradin : An Enpirical Analysis. The Accounting Review.

Suwiknyo, D. (2010). Analisi Laporan Keuangan Perbankan Syariah. Yogyakarta: Pustaka Pelajar.

Widyaningdyah, A. U. (2001). Analisis Faktor-Faktor yang Berpengaruh terhadap Earning Management pada Perusahaan Go Public di Indonesia. Ekonomi Akuntansi.

Wolfe, D. T., \& Hermanson, D. R. (2004). The Fraud Diamond; Considering the Four Elements of Fraud. The CPA Journal, 2-6.

Yulia, A. W., \& Basuki. (2016). Studi Financial Statement Fraud pada Perbankan yang Terdaftar di BEI. Ekonomi dan Bisnis. 